\title{
Experimental Studies on Cracking and Local Strain Behaviors of Rock-Like Materials with a Single Hole before and after Reinforcement under Biaxial Compression
}

\author{
Jian Liao $\mathbb{D}$, ${ }^{1,2}$ Yanlin Zhao $\mathbb{D},{ }^{1,2}$ Liming Tang $\mathbb{D}$, ${ }^{1,2}$ and Qiang Liu $\mathbb{D} \mathbb{D}^{1,2}$ \\ ${ }^{1}$ School of Resource Environment and Safety Engineering, Hunan University of Science and Technology, \\ Xiangtan 411201 Hunan Province, China \\ ${ }^{2}$ Work Safety Key Lab on Prevention and Control of Gas and Roof Disasters for Southern Coal Mines, Hunan University of Science \\ and Technology, Xiangtan, 411201 Hunan Province, China
}

Correspondence should be addressed to Yanlin Zhao; yanlin_8@163.com

Received 15 September 2020; Revised 16 December 2020; Accepted 17 March 2021; Published 1 April 2021

Academic Editor: Mohammad Sarmadivaleh

Copyright $\odot 2021$ Jian Liao et al. This is an open access article distributed under the Creative Commons Attribution License, which permits unrestricted use, distribution, and reproduction in any medium, provided the original work is properly cited.

In deep underground engineering, circular roadways are widely used; many rock engineering problems can usually be simplified as mechanical analysis of rock structures with holes. To reveal the influence of intrahole reinforcement on the mechanical properties of rock with a single hole, this paper takes the single-hole rock-like material specimens with different reinforcement conditions as the research object. The RYL600 rock shear rheometer was used to conduct biaxial compression tests and, combined with HD industrial cameras and high-precision strain gauges, to study the effects of different reinforcement thicknesses and different lateral pressure on the mechanical properties of single-hole rock-like materials during the total stress and strain process. The thickness of the reinforced aluminum alloy pipe in the whole test is divided into four types: $0,1,1.5$, and $2 \mathrm{~mm}$. Under different reinforcement conditions, it is divided into 4 series of $0,0.5,1$, and $1.5 \mathrm{MPa}$ according to the different lateral pressure. Research shows the following: (1) Under the same lateral pressure, as the reinforcement thickness of the aluminum alloy tube increases, the reinforcement effect of the aluminum alloy tube on the specimen increases, and the strength of the reinforced specimen is increased by $1.42 \% \sim 33.04 \%$ compared with the strength of the unreinforced specimen; under the same reinforced thickness of the aluminum tube, the peak strength of the specimen increases with the increase of lateral pressure, and the peak strength of the specimen with lateral pressure is $3.34 \% \sim 50.26 \%$ higher than that of the specimen without lateral pressure. (2) Increasing the lateral pressure can significantly reduce the primary tensile cracks of the specimen. As the reinforcement thickness increases, the primary tensile cracks and remote cracks of the specimen are significantly reduced, and the failure surface of the specimen gradually tends to the middle of the sample. (3) The failure modes of specimens with holes can be divided into five types: single bevel type I, single bevel type II, single bevel type III, bevel T type, and single part shear type. All of these five failure modes are shear cracks that develop into fracture surfaces, while remote cracks and primary tensile cracks do not develop into fracture surfaces.

\section{Introduction}

In deep underground engineering, the stress concentration around the circular tunnel is low, so it is widely used in underground engineering [1]. The strength, deformation, and failure characteristics of rock with holes are much more complicated than those of intact rock [2]; especially, the propagation and evolution of cracks around the holes [3, 4] have an important impact on construction safety and production efficiency.
To investigate the mechanical properties of rocks with holes, laboratory compression failure tests on rocks with holes have been widely used. For example: Steen et al. [5] studied the influence of the stress gradient on the stress concentration at the tip of the active defect on the origin of the specific crack behavior in the diameter-loaded disk with holes; Lajtai and Lajtai [6] studied the evolution of cracks around rock cavities through a multiaxial compression test and analyzed the influence of confining pressure on the rock 


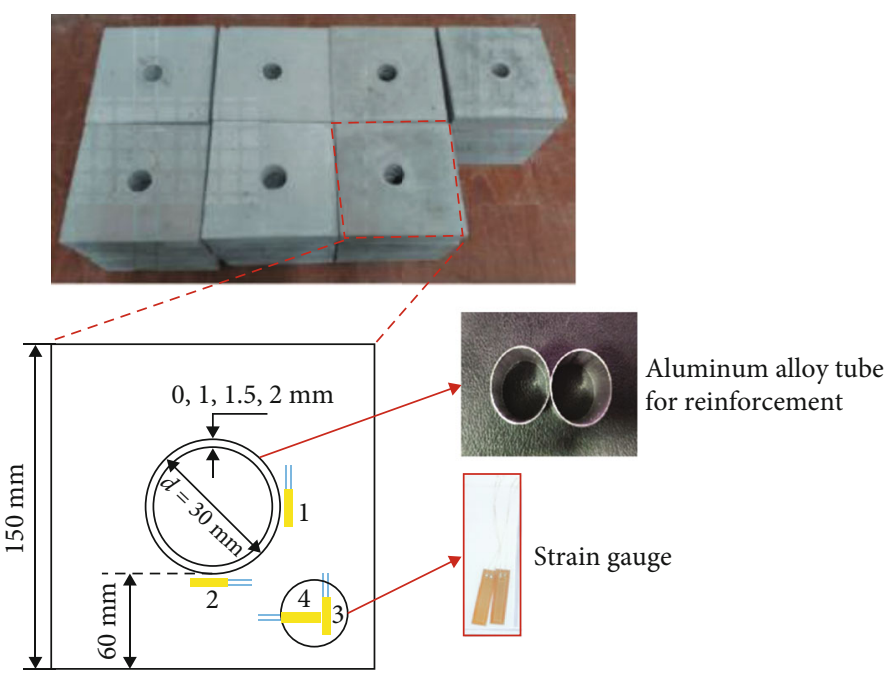

FIgURE 1: Structure diagram of rock-like materials and the position of the strain gauges.

TABLE 1: Details of all tested rock-like specimens.

\begin{tabular}{lccccc}
\hline Specimen & $\begin{array}{c}\text { Thickness, } \\
\mathrm{mm}\end{array}$ & $\begin{array}{c}\text { Lateral } \\
\text { pressure } \\
\sigma_{2}, \mathrm{MPa}\end{array}$ & $\begin{array}{c}\text { Peak } \\
\text { strength, } \\
\mathrm{MPa}\end{array}$ & $\begin{array}{c}\text { Density } \\
\rho, \mathrm{g} / \mathrm{cm}^{3}\end{array}$ & $\begin{array}{c}\text { Elastic } \\
\text { modulus } \\
E, \mathrm{GPa}\end{array}$ \\
\hline SN0-1 & & 0.0 & 19.78 & 2.01 & 2.08 \\
SN0-2 & 0.0 & 0.5 & 19.47 & 1.99 & 1.93 \\
SN0-3 & & 1.0 & 24.95 & 2.02 & 2.22 \\
SN0-4 & & 1.5 & 26.36 & 1.96 & 1.61 \\
SN10-1 & & 0.0 & 19.18 & 1.98 & 2.06 \\
SN10-2 & \multirow{2}{*}{1.0} & 0.5 & 23.32 & 2.01 & 2.38 \\
SN10-3 & & 1.0 & 26.33 & 2.05 & 2.59 \\
SN10-4 & & 1.5 & 27.69 & 2.13 & 2.32 \\
SN15-1 & & 0.0 & 20.06 & 1.99 & 2.05 \\
SN15-2 & \multirow{2}{*}{1.5} & 0.5 & 23.89 & 2.03 & 2.03 \\
SN15-3 & & 1.0 & 26.46 & 1.97 & 2.51 \\
SN15-4 & & 1.5 & 28.62 & 2.08 & 2.42 \\
SN20-1 & & 0.0 & 23.34 & 1.99 & 2.09 \\
SN20-2 & \multirow{2}{*}{2.0} & 0.5 & 24.12 & 2.03 & 2.39 \\
SN20-3 & & 1.0 & 26.62 & 1.97 & 1.93 \\
SN20-4 & & 1.5 & 35.07 & 2.05 & 2.16 \\
\hline
\end{tabular}

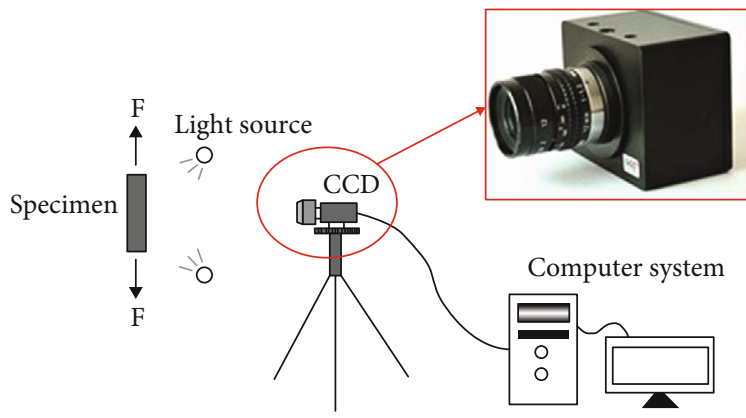

Figure 2: HD industrial camera and strain gauge arrangement drawing. failure mechanism; Fakhimi et al. [7] studied the acoustic emission characteristics of prefabricated circular cavity sandstone specimens during the failure process through biaxial compression tests; Yin et al. [8] studied the mechanical behavior and crack coalescence of sandstone specimens containing fissure-hole combined flaws under uniaxial compression; Hou [9] conducted the AE experimental study on the damage and failure processes of rock with hole.

The studied above is mainly a single circular hole, and the influence of hole diameter, other shapes of holes, and multiple holes on rock deformation and mechanical properties is not considered. Therefore, Rong et al. [10] conducted uniaxial compression tests on rock samples with different pore radii and studied the influence of the pore size effect on the rock uniaxial compression strength and failure characteristics, and Cui et al. [11] conducted uniaxial compression tests on rock materials with different apertures and analyzed the effects of different apertures on rock failure modes and deformation; Gay [12] studied the crack propagation mechanism of the rock wall through compression tests on two kinds of rocks with circular holes and rectangular holes; Tao et al. [13] conducted static and dynamic load tests on elliptical hole bored granodiorite rocks under four different loading rates; Xie et al. [14] tested different cubic samples with and without holes to study the influence of holes on the subcritical propagation of shear cracks. They believed that two symmetrical additions were added to the original crack plane of the rock sample. Appropriate holes are potentially effective in stopping rock cracks; Cui et al. [15] conducted a compressive strength test on double round-hole specimens and analyzed the influence of double round-hole cracks with different inclination angle cracks, different hole center distances, and confining pressure on the strength of the specimen; Janeiro et al. [16] conducted uniaxial compression tests on gypsum specimens with fillings and studied the influence of fillings and pore shapes on the mechanical properties of rock-like materials.

Many scholars also use numerical simulation to study rocks with holes $[17,18]$, and Wong et al. [19] studied the 


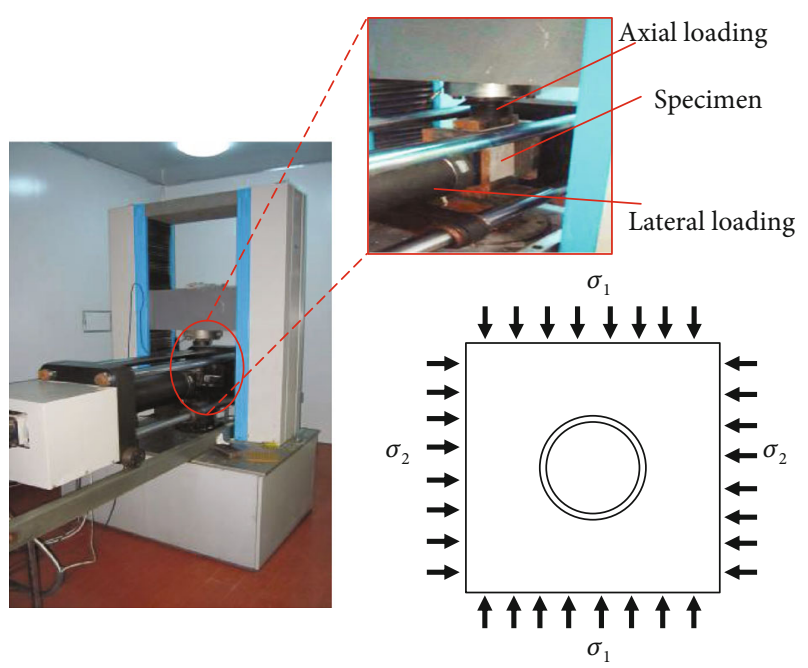

FIGURE 3: RYL600 rock mechanics shear rheology machine and biaxial compression loading ( $\sigma_{1}$ : axial pressure, $\sigma_{2}$ : lateral pressure).

influence of factors such as specimen size and aperture on the peak strength, crack growth, and failure mode based on the results of laboratory physical tests and combined with MFPA2D numerical simulation; Wang et al. [20] used RFPA2D to study the influence of sample homogeneity and confining pressure on the initiation and damage of rock with holes; Li et al. [21] used PFC2D to analyze the effects of prefabricated hole shape, confining pressure, and rock heterogeneity on mechanical properties and crack propagation.

Although a lot of research results have been made in the study of the mechanical properties of rock with holes, the existing research seldom pays attention to the influence of the reinforcement of holes on the mechanical properties of the rock with holes. Therefore, this paper takes the singlehole rock-like material specimens with different reinforcement conditions as the research object and conducts biaxial compression tests under different lateral pressures and, combined with HD industrial camera and high-precision strain gauges, a comparative study of the cracking and local strain behaviors of rock-like materials with single hole before and after reinforcement. The results of this study are of great significance for a deep understanding of the failure mechanism of defective rocks, and at the same time, it can provide a corresponding theoretical basis for evaluating the stability of tunnels and other engineering surrounding rocks.

\section{Test Plan}

2.1. Specimen Preparation and Implementation of Reinforcement. A cement mortar with a mass ratio of $m_{\text {cement }}: m_{\text {sand }}: m_{\text {water }}=26: 25: 10$ was used to pour a 150 $\mathrm{mm} \times 30 \mathrm{~mm} \times 150 \mathrm{~mm}$ rock-like specimen with a single hole in a cast iron mold. When pouring, a reinforced aluminum alloy pipe with an outer diameter of $30 \mathrm{~mm}$ is placed vertically in the center of the mold for reinforcement in the hole. The thickness of the aluminum alloy tube is divided into four types: $0,1,1.5$, and $2 \mathrm{~mm}$. The chemical composition of aluminum alloy tube is $98.36 \% \mathrm{Al}, 0.47 \% \mathrm{Si}, 0.3 \%$ $\mathrm{Fe}, 0.08 \% \mathrm{Cu}, 0.07 \% \mathrm{Mn}, 0.62 \% \mathrm{Mg}, 0.01 \% \mathrm{Cr}$, and $0.09 \%$
$\mathrm{Zn}$, tensile strength is $226 \mathrm{MPa}$, and hardness is HW13. The size and structure of the specimen are shown in Figure 1. The specimen was tested after curing for 28 days at room temperature.

2.2. Test Equipment and Procedures. The RYL600 rock shear rheometer was used to conduct biaxial compression tests on 4 types of rock specimens with different reinforcement thicknesses. Each type is divided into 4 series of $0,0.5,1$, and $1.5 \mathrm{MPa}$ according to the different lateral pressure. The specific grouping is shown in Table 1.

During the test, high-precision strain gauges, static strain gauges, and HD industrial cameras (Figure 2) were used to monitor the rupture process of the specimen, and the strain gauges were arranged near the right and the bottom of the center hole, and away from the center hole (Figure 1). To synchronize the recording time of the shear rheometer, HD industrial camera, and static strain gauge, three researchers operate the three instruments synchronously. The steps of the test are as follows: (1) Arrange strain gauges on the surface of the specimen, connect the strain gauges, and arrange HD industrial cameras and light sources. (2) Install the specimen and preload it. Load the axial pressure to $2 \mathrm{kN}$ at a rate of $100 \mathrm{~N} / \mathrm{s}$, load the lateral pressure to $2 \mathrm{kN}$ at a rate of $100 \mathrm{~N} / \mathrm{s}$, and the specimen is completely in contact with the indenter. (3) Load the lateral pressure to the design value at a rate of $0.01 \mathrm{MPa} / \mathrm{s}$. (4) Using displacement control, load axial pressure at a rate of $0.1 \mathrm{~mm} / \mathrm{min}$ until the specimen occurs instability failure (Figure 3 ).

\section{Test Results}

3.1. Stress-Strain Curves. The stress-strain curve of the biaxial compression test is shown in Figure 4. When the lateral pressure is $0 \mathrm{MPa}$, the elastic modulus of each specimen is relatively close, and the linear elastic stage is relatively steep. It can be seen that the stress-strain curve has the properties of plastic-elastic-plastic, and the overall curve is S-shaped, mainly divided into 4 stages (Figure $4(\mathrm{~d})$ ): OA (closed stage of micropores and microcracks), $\mathrm{AB}$ (elastic deformation stage), $\mathrm{BC}$ (plastic deformation stage), and CD (stress drop stage).

(1) Under the same lateral compression, the peak strength increases with the increase of the reinforced thickness of the aluminum alloy tube (Figure 5). When the lateral pressure is $0 \mathrm{MPa}$, the strength of specimens SN0-1, 10-1, 15-1, and $20-1$ is $19.78,19.18,20.06$, and $23.34 \mathrm{MPa}$, respectively; in addition to SN10-1, the specimens SN151 and SN20-1 with the thickness of $1.5 \mathrm{~mm}$ and $2 \mathrm{~mm}$ were strengthened, and their peak strength was increased by $1.42 \%$ and $18 \%$. When the lateral pressure is $0.5 \mathrm{MPa}$, the strength of specimens SN0-2, 10-2, 15-2, and 20-2 with holes is 19.47, $23.32,23.89$, and $24.12 \mathrm{MPa}$, respectively. The peak strength of SN10-2, 15-2, and 20-2 specimens with thickness of $1 \mathrm{~mm}, 1.5 \mathrm{~mm}$, and $2 \mathrm{~mm}$ increased by $19.78 \%, 22.7 \%$, and $23.88 \%$, respectively. When the 


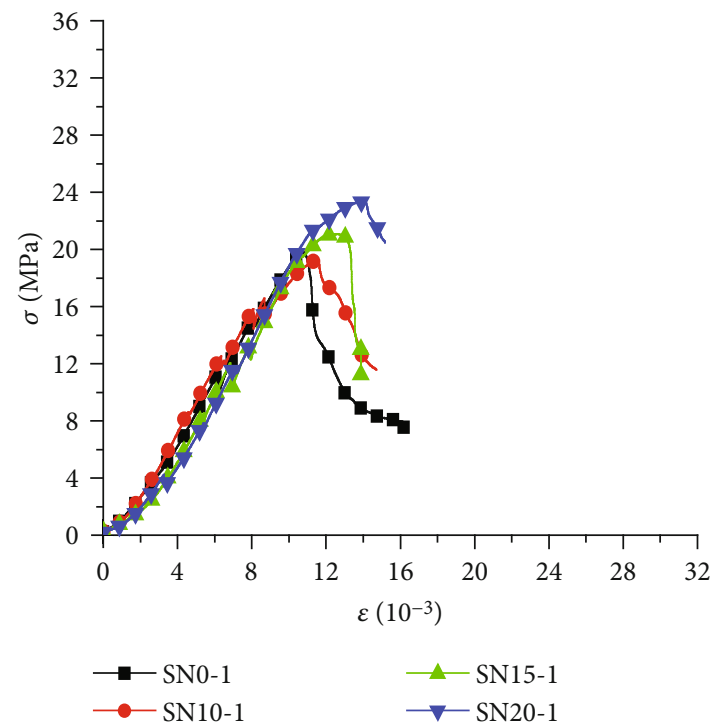

(a)

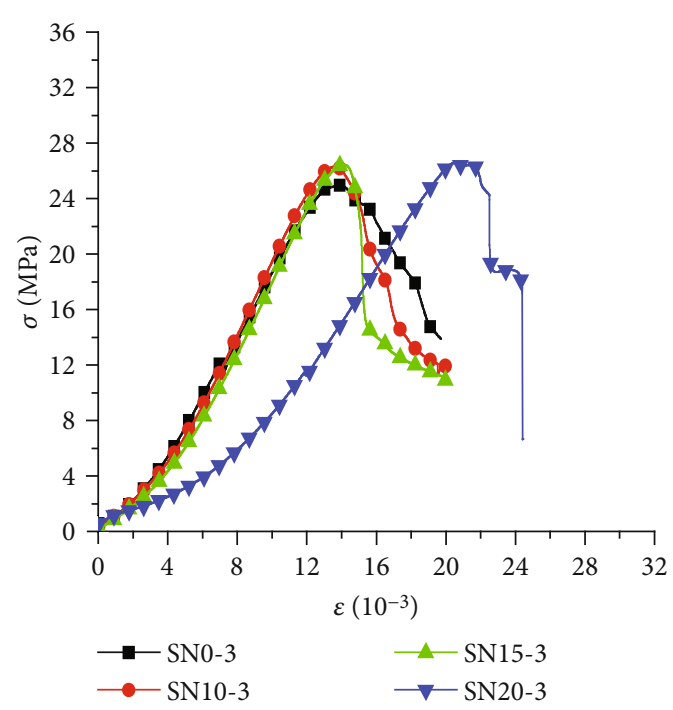

(c)

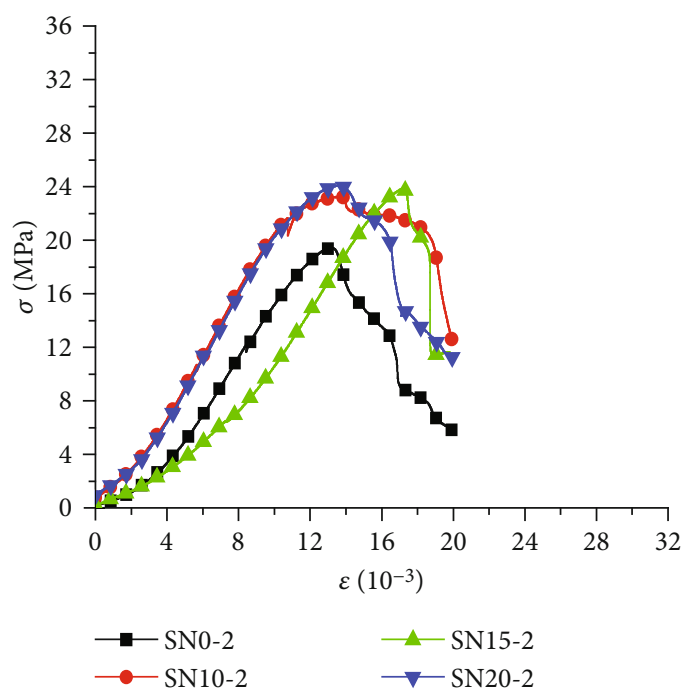

(b)

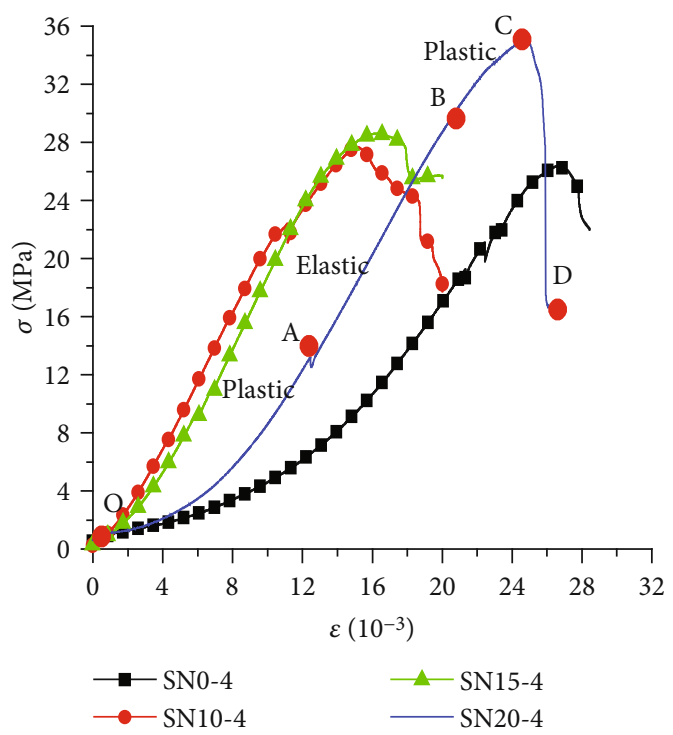

(d)

Figure 4: Axial stress-strain curve of the specimen under the same reinforcement condition and different lateral pressure conditions. (a) Lateral pressure is $0 \mathrm{MPa}$. (b) Lateral pressure is $0.5 \mathrm{MPa}$. (c) Lateral pressure is $1 \mathrm{MPa}$. (d) Lateral pressure is $1.5 \mathrm{MPa}$.

lateral pressure is $1 \mathrm{MPa}$, the strength of specimens SN0-3, 10-3, 15-3, and 20-3 with holes is 24.95, $26.33,26.46$, and $26.62 \mathrm{MPa}$, respectively. The peak strength of specimens SN10-3, 15-3, and 20-3 with the reinforcement thickness of $1 \mathrm{~mm}, 1.5 \mathrm{~mm}$, and $2 \mathrm{~mm}$ is increased by $5.53 \%, 6.05 \%$, and $6.69 \%$, respectively. When the lateral pressure is $1.5 \mathrm{MPa}$, the strength of specimens SN0-4, 10-4, 15-4, and 20-4 with holes is 26.36, 27.69, 28.62, and 35.07 MPa, respectively. The peak strength of specimens SN10-4, 15-4, and 20-4 with the reinforcement thickness of $1 \mathrm{~mm}, 1.5 \mathrm{~mm}$, and $2 \mathrm{~mm}$ is increased by $5.05 \%, 8.57 \%$, and $33.04 \%$, respectively
(2) The peak strength of the rock-like specimens will increase with the increase of the lateral pressure under the same reinforced thickness of the aluminum alloy tube. The reinforcement thickness of the aluminum alloy tube of the specimens SN0-1, 0-2, 0-3, and $0-4$ is $0 \mathrm{~mm}$, its strength is $19.78,19.47,24.95$, and 26.36 MPa, respectively, compared with SN0-1 with a lateral pressure of $0 \mathrm{MPa}$, and the peak strength of SN0-2, $0-3$, and $0-4$ increased by $26.14 \%$ and $33.27 \%$, respectively. The reinforced thickness of the aluminum alloy tube of the specimens SN10-1, 10$2,10-3$, and $10-4$ is $1.0 \mathrm{~mm}$, its strength is 19.18 , $23.32,26.33$, and $27.69 \mathrm{MPa}$, respectively, and compared with SN10-1 with a lateral pressure of $0 \mathrm{MPa}$, 


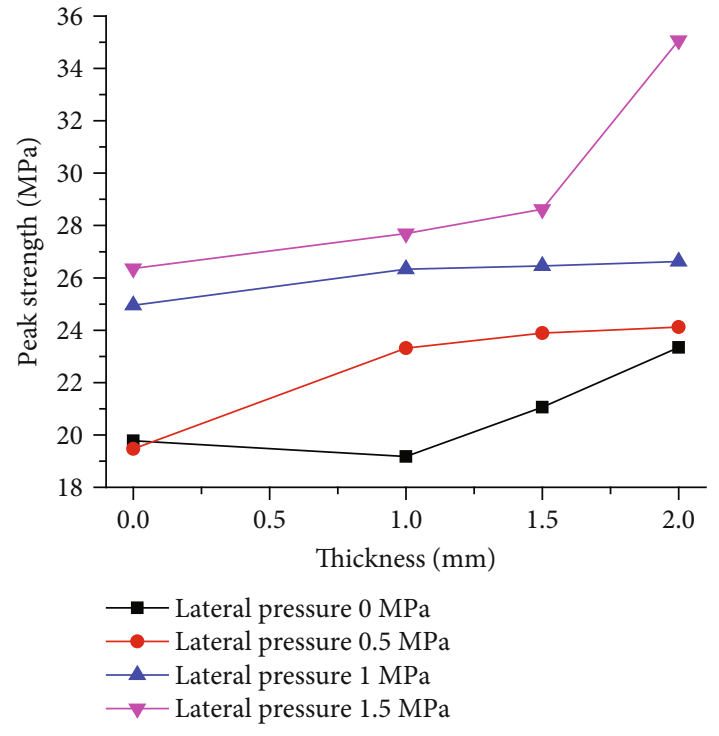

FIGURE 5: Comparison of peak strength of specimens reinforced with different thicknesses of aluminum alloy tube under the same pressure.

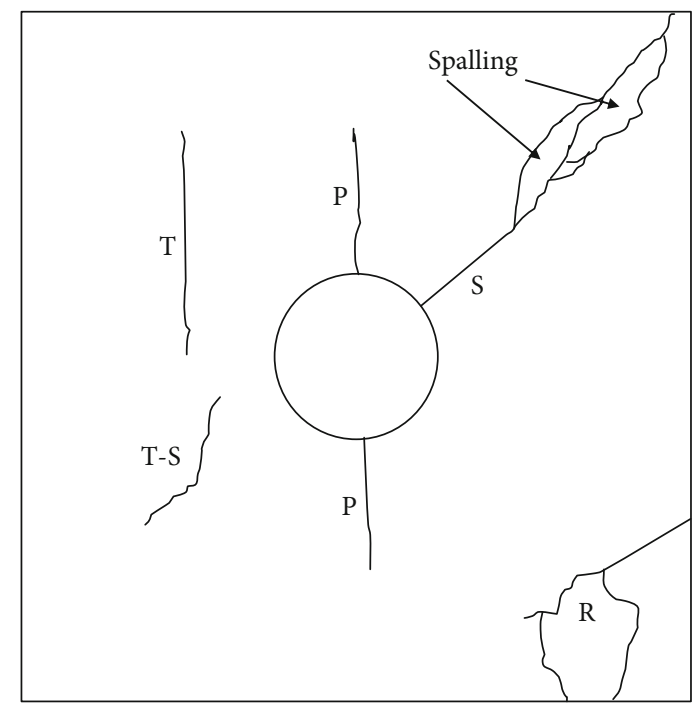

FIgURE 6: Types of cracks around circular holes (T: tensile crack, S: shear crack, T-S: tensile-shear crack R: remote crack, and P: primary crack).

the peak strength of SN10-2, 10-3, and 10-4 increased by $21.59 \%, 37.28 \%$, and $44.37 \%$, respectively. The reinforcement thickness of the aluminum alloy tube of the specimens SN15-1, 15-2, 15-3, and 15-4 is $1.5 \mathrm{~mm}$, its strength is $21.06,23.89,26.46$, and $28.62 \mathrm{MPa}$, respectively, and compared with SN15-1 with a lateral pressure of $0 \mathrm{MPa}$, the peak strength of SN15-2, 15-3, 15-4 increased by $13.44 \%, 25.64 \%$, and $35.9 \%$, respectively. The reinforcement thickness of the aluminum alloy tube of the specimens SN20-1, $20-2,20-3$, and $20-4$ is $2.0 \mathrm{~mm}$, and its strength is $23.34,24.12,26.62$, and $35.07 \mathrm{MPa}$, respectively; compared with $\mathrm{SN} 20-1$ with a lateral pressure of $0 \mathrm{MPa}$, the peak strength of SN20-2, 20-3, and 20-4 increased by $3.34 \%, 14.05 \%$, and $50.26 \%$, respectively.

3.2. Failure Mode. For specimens with a single hole under load, cracks around the hole are generally divided into five types (Figure 6): primary cracks, shear cracks, tensile cracks, tensile-shear cracks, and remote cracks. The primary cracks exist on the top and bottom edges of the center hole. Remote cracks are cracks far away from the center hole; there are tensile cracks and shear cracks in the remote cracks, as well as tensile-shear cracks. Figure 7 shows the failure morphology of the rock specimen with holes and the schematic diagram of the failure crack of the specimen under biaxial compression.

It can be found that under the same reinforcement conditions, when the lateral pressure is lower, the specimens have more tensile cracks, the tensile stress of the specimen is obvious, the specimen is destroyed quickly, and the strength of the specimen is low. With the increase of the lateral pressure, the tensile cracks are clearly reduced, and the tensile cracks of the specimens are difficult to expand rapidly when the specimens are compressed, only the cracks on the upper part of the holes expand to failure, and the strength of the specimens is higher. Under the same lateral pressure conditions, when the reinforcement thickness is low, there are more remote cracks and primary tensile cracks in the specimen. With the increase of the reinforcement thickness, the remote cracks and primary tensile cracks are significantly reduced, and the failure surface of the specimen gradually resides in the middle of the specimen, which indicates that the reinforcement of the aluminum alloy tube has an obvious positive effect. The aluminum alloy tube has a large pressurebearing effect at the center position, which makes the shear cracks on both sides preferentially expand due to the failure of the specimen, forming a fracture surface.

The failure morphology of rock specimens with holes under biaxial compression can be divided into five types (Figure 8). These five types of failure modes are all formed by the propagation of shear cracks. The remote cracks and primary tensile cracks do not propagate to the fracture surface.

The single bevel type I failure mode is characterized by the crack surface from bottom left to upper right, and the single bevel type II failure mode is characterized by the crack surface from upper left to lower right. The specimens belonging to these two types of failure modes are SN0-3, SN15-2, SN15-3, SN20-2, SN20-4, SN0-2, and SN10-2; it is noted that the lateral pressure of all specimens in this failure mode is greater than $0 \mathrm{MPa}$, which indicates that the shear effect of the specimens containing holes with lateral pressure greater than $0 \mathrm{MPa}$ is obvious and the failure of the specimens is relatively regular. The strength of the specimens was 24.95 , $23.89,26.46,24.12,30.07,19.47$, and $23.32 \mathrm{MPa}$, respectively. The overall strength was relatively high, indicating that the specimens had strong bearing capacity when there was lateral pressure; the characteristic of the single bevel type III failure mode is that the crack surface is roughly in the middle of the specimen. The specimens belonging to this type of failure 


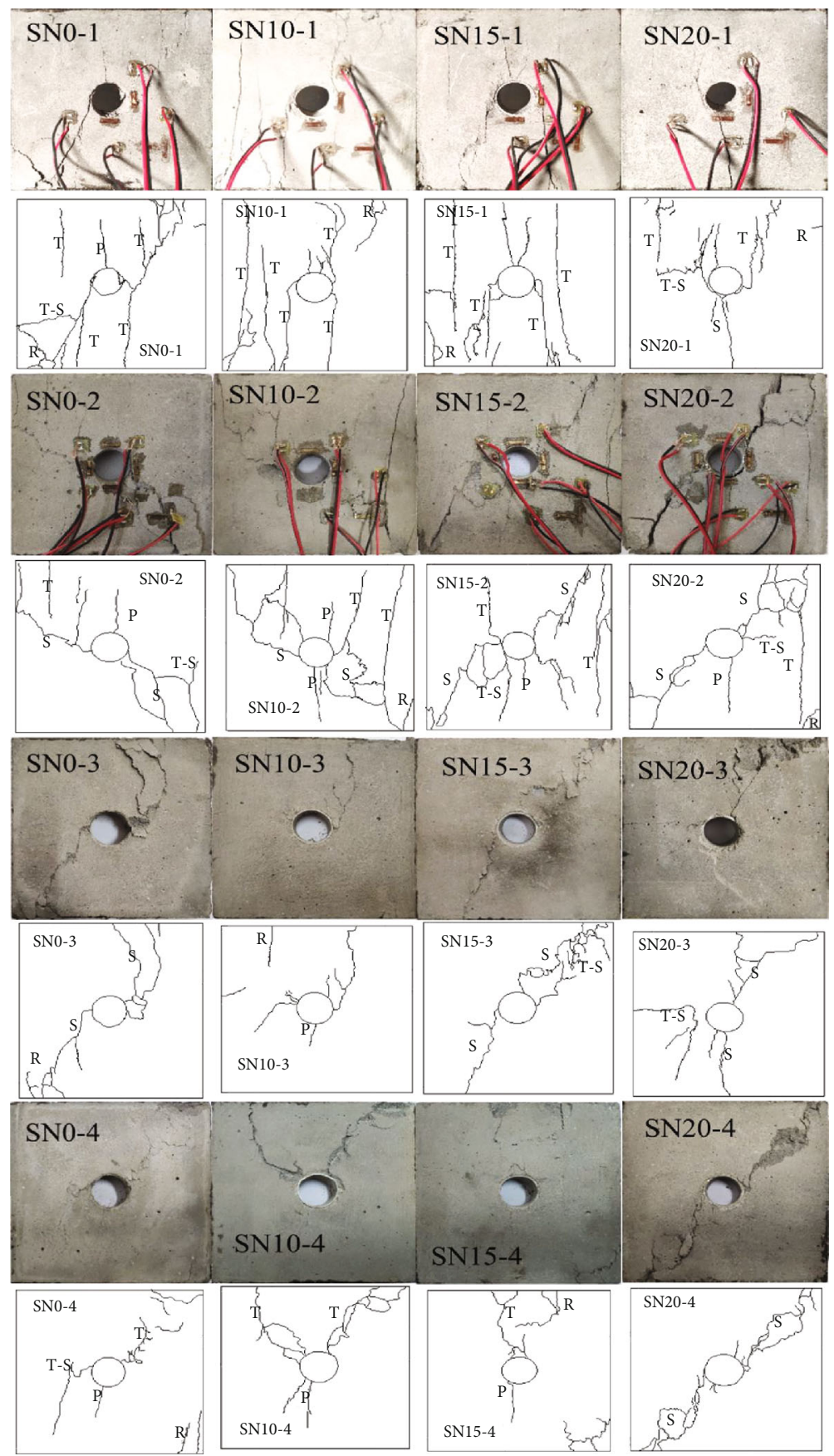

FIgURE 7: Failure morphology and schematic diagram of all specimens (T: tensile crack, S: shear crack, T-S: tensile-shear crack R: remote crack, and P: primary crack).

mode are only SN20-1 and SN20-3, and the strength of the specimens is 23.34 and $26.62 \mathrm{MPa}$, respectively. It was noted that the thickness of the reinforced aluminum alloy tube of the two specimens was $20 \mathrm{~mm}$, and the strength of the specimens was almost the same, indicating that the reinforcement of the aluminum alloy tubes played a clearly positive role. The aluminum tube has a great pressure-bearing effect at the center position, so that the shear cracks on both sides will preferentially expand, causing damage to the specimen; the characteristic of the bevel $\mathrm{T}$ failure mode is that the inclined plane is roughly in the middle of the specimen, and T-shaped failure occurs. The specimens belonging to this type of failure mode are SN0-1, SN10-1, and SN15-1. The strength of the specimens is $19.78,19.18$, and $21.06 \mathrm{MPa}$, respectively. Clearly, the lateral pressure of the specimens in this failure mode is $0 \mathrm{MPa}$, and the strength of the specimens is relatively low; there are more remote cracks and primary tensile cracks in these specimens. The specimen is no longer subjected to pressure in the lateral direction, which leads to more tensile cracks, and the tensile stress is more obvious, so that the 


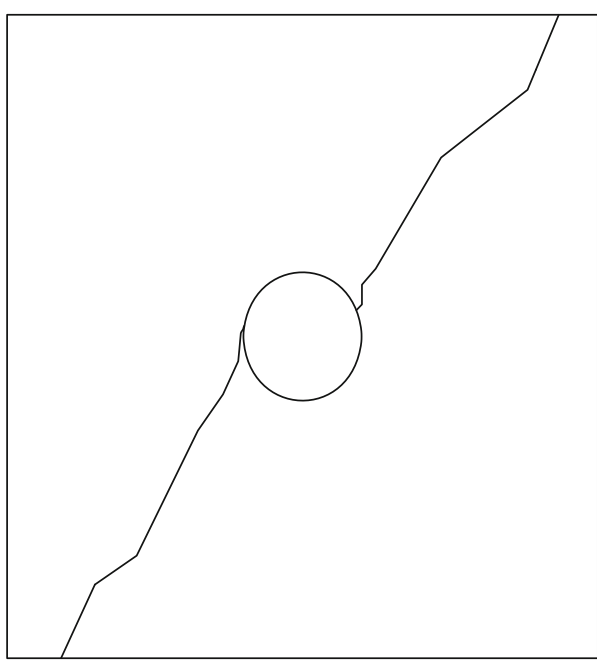

(a)

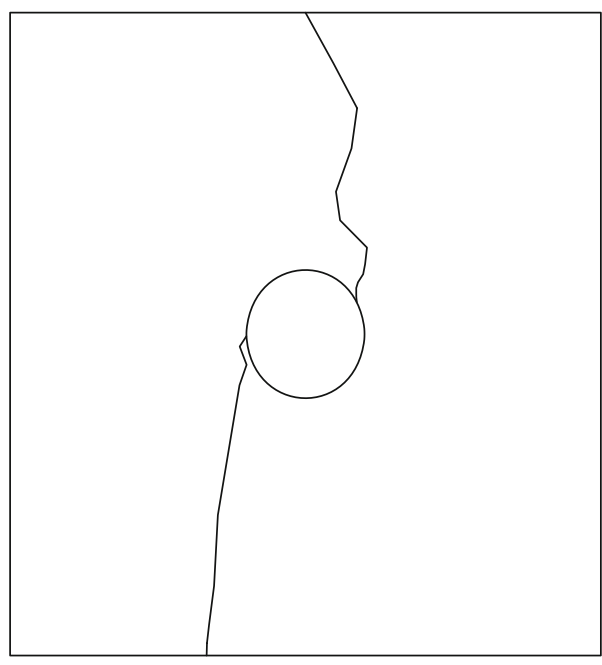

(c)

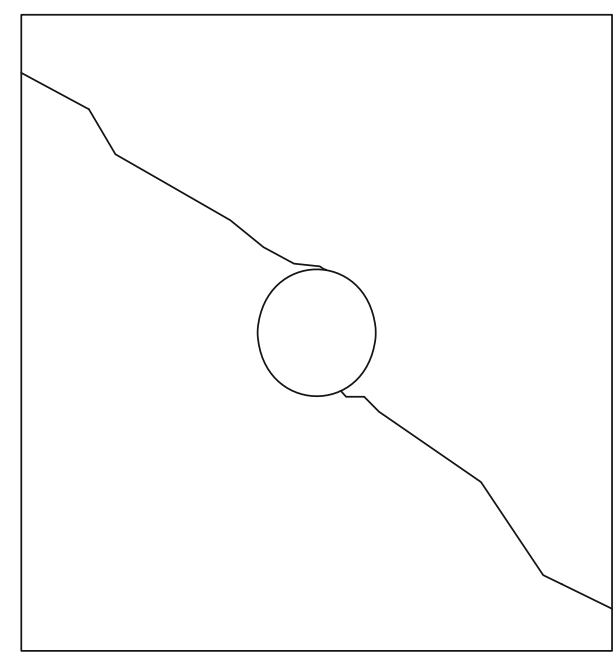

(b)

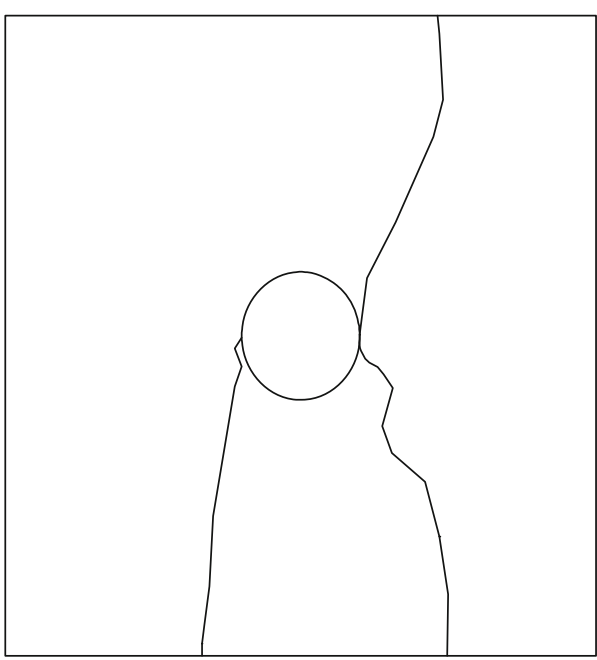

(d)

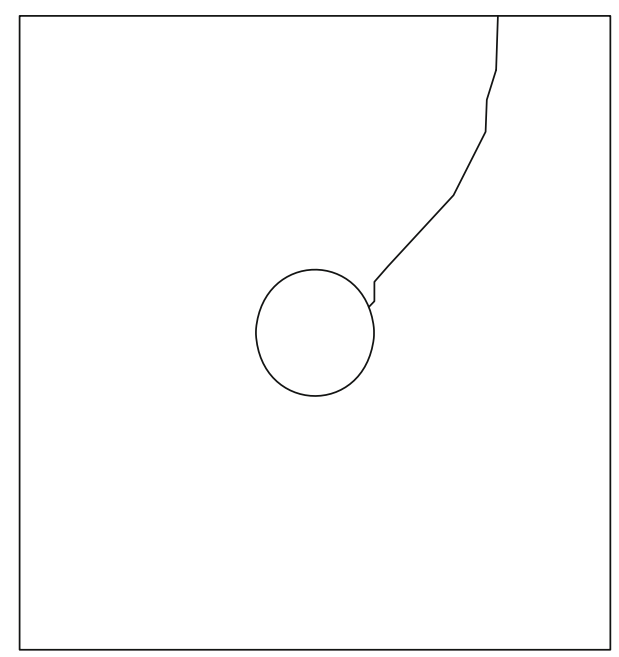

(e)

FIGURE 8: Classification of failure modes of specimens with a hole. (a) Single bevel type I. (b) Single bevel type II. (c) Single bevel type III. (d) Bevel T type. (e) Single part shear type. 


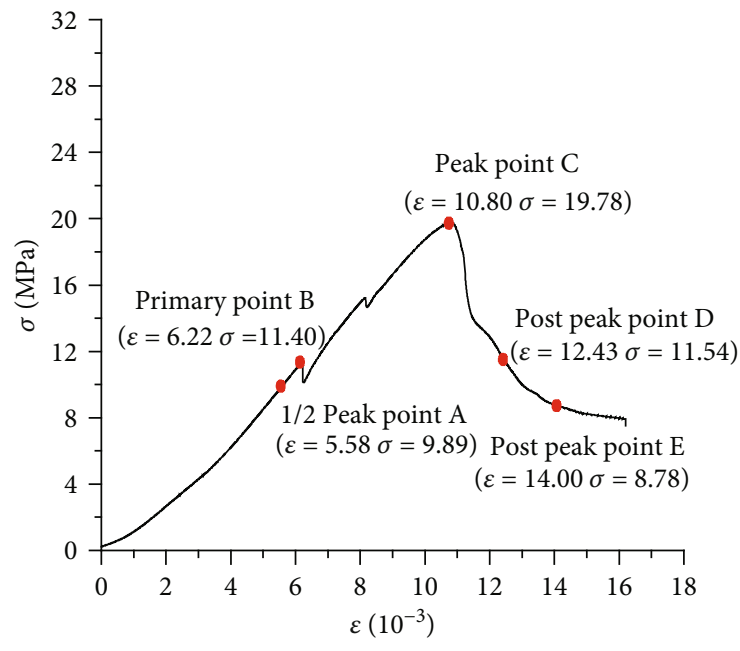

(a)

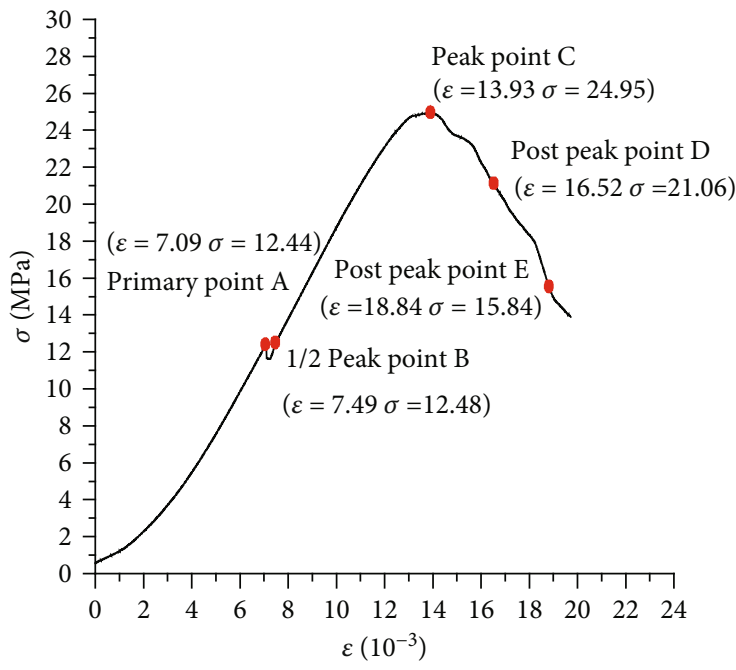

(c)

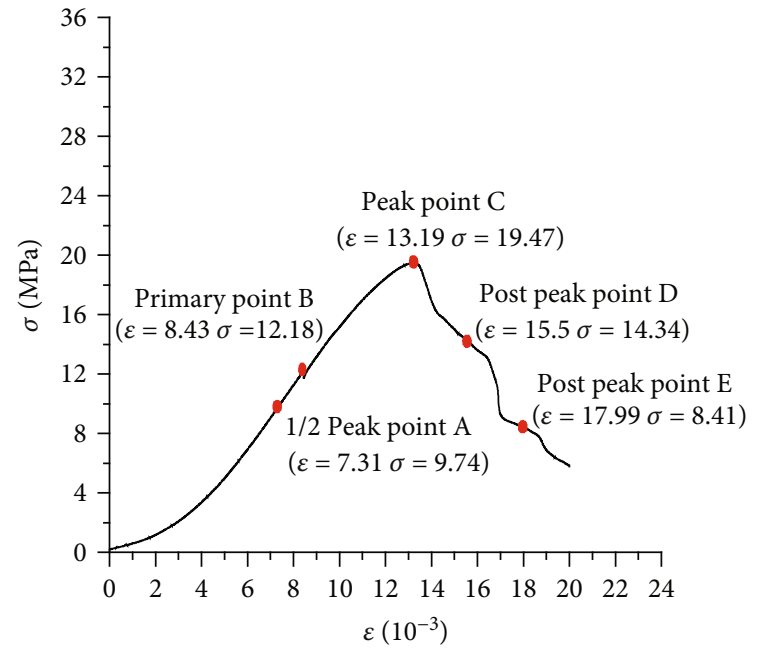

(b)

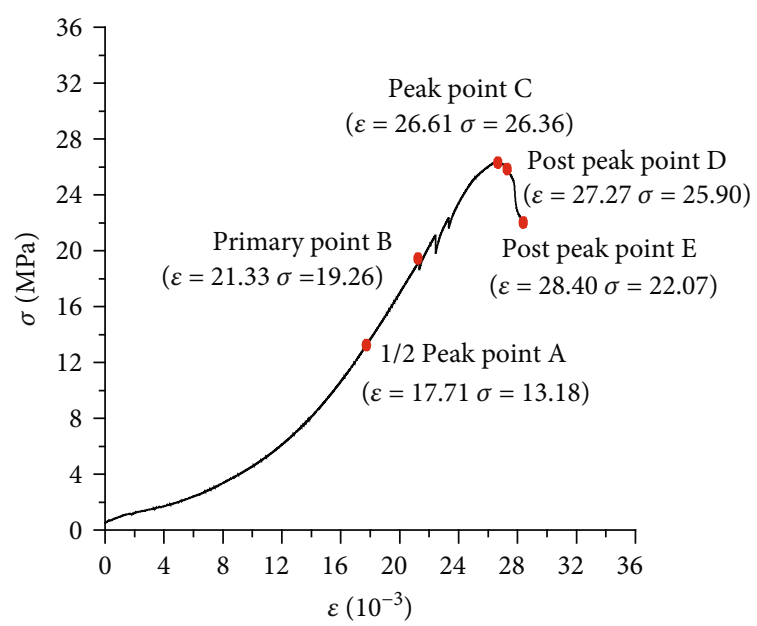

(d)

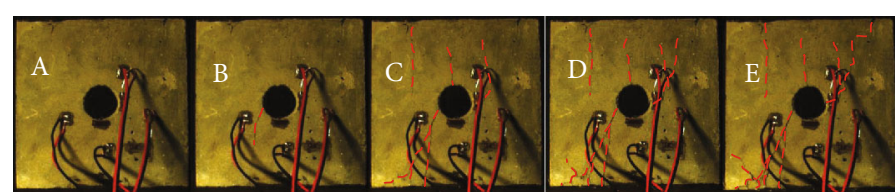

(e)

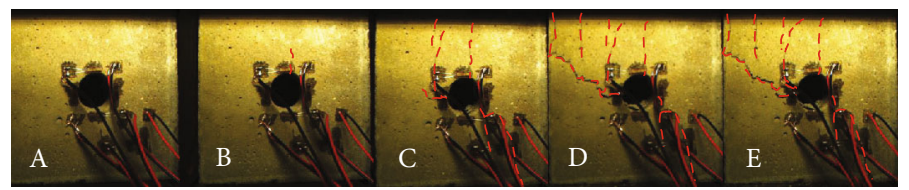

(f)

FIgure 9: Continued. 


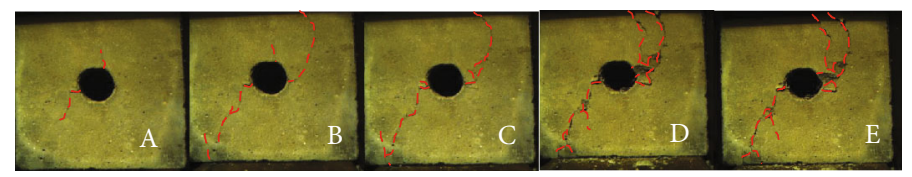

(g)

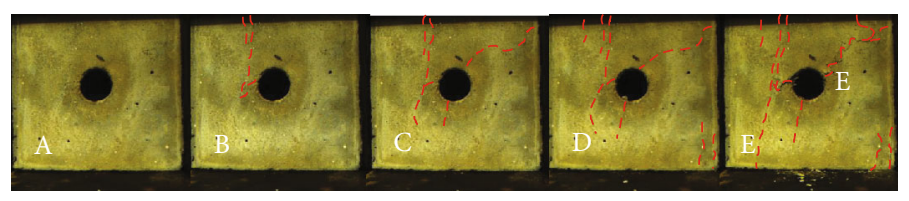

(h)

FIGURE 9: Comparison of crack growth of specimens when the lateral pressure is $0 \mathrm{MPa}$. (a) Details of SN0-1 stress-strain curve. (b) Details of SN0-2 stress-strain curve. (c) Details of SN0-3 stress-strain curve. (d) Details of SN0-4 stress-strain curve. (e) SN0-1 crack growth process. (f) SN0-2 crack growth process. (g) SN0-3 crack growth process. (h) SN0-4 crack growth process.

damage is faster and the strength of the specimen is lower; the shear failure mode of a single part shear type is characterized by shear failure, and the failure surface appears on the upper part of the specimen. The specimens belonging to this type of failure mode are SN0-4, SN10-3, SN10-4, and SN154 , and the strength is $26.36,26.33,27.69$, and $28.62 \mathrm{MPa}$, respectively. The specimens in this type of failure mode have the highest strength. This is due to the fact that there are fewer tensile cracks and relatively large lateral pressure. It is difficult for a certain part of the specimen to propagate quickly under compression, only the cracks in the upper part of the hole spread to failure.

\section{Discussion}

4.1. Crack Propagation Law and Stress Characteristics. To study the crack propagation law of rock-like materials with a single hole, the crack propagation path of the specimen was captured by an HD industrial camera during the biaxial compression test. The failure mode of the specimen shows that the remote cracks can only be seen when the lateral pressure is $0 \mathrm{MPa}$. Therefore, take the specimens SN0-1, 0-2, 0-3, and $0-4$ as examples (Figure 9).

For SN0-1, 1/2 peak point $A$ is before primary point $B$, $\sigma_{i}=11.40 \mathrm{MPa}$. According to the image captured by the $\mathrm{HD}$ industrial camera, the primary crack is the shear crack on the left lateral of the hole, $\sigma_{p}=19.78 \mathrm{MPa}$ (point C). There are 4 main cracks, including 2 shear cracks, 1 tensile crack around the hole, and 1 remote crack. At point $\mathrm{D}$, after the peak, the cracks of the piece expand again, and the shear crack on the right lateral of the hole has expanded into another crack; at point E after the peak, the stress has dropped to about $58 \%$ of the peak stress, and no new cracks are generated, the shear cracks on the left and right sides of the hole expand into an inclined plane.

For SN0-2, the lateral pressure is $0.5 \mathrm{MPa}$, and point $\mathrm{A}$ is also before the primary point $\mathrm{B}, \sigma_{i}=12.18 \mathrm{MPa}$, and it is similar to specimen SN0-1. According to the image captured by the HD industrial camera, the primary crack is a tensile crack on the upper part of the hole, and it is also similar to the specimen SN0-1. $\sigma_{p}=19.47 \mathrm{MPa}$ (point C), at this time, and 3 main cracks appeared, all distributed around the hole, 2 shear cracks on the side of the hole, and 1 tensile crack on the upper part of the hole. At point $\mathrm{E}$ after the peak, the stress has dropped to about $43 \%$ of the peak stress, and no new cracks are generated, the shear cracks on the left and right laterals of the hole expand into a reverse slope.

For SN0-3, the lateral pressure is $1.0 \mathrm{MPa}$, point $\mathrm{A}$ is the crack primary point before point $\mathrm{B}$, and the two points are very close (only about $35 \mathrm{~s}$ apart), $\sigma_{i}=12.44 \mathrm{MPa}$, and it is similar to SN0-1 and SN0-2. According to the image captured, the primary crack is a tensile crack on the upper part of the hole. The peak stress was $\sigma_{p}=24.95 \mathrm{MPa}$ (point C); at this point, two main cracks appear, all distributed around the hole, which are shear cracks near the hole. At point D after the peak, the specimen cracks expanded again, the shear crack on the right side of the hole developed into another crack, until the point $\mathrm{E}$ after the peak, there were no new cracks, and the shear cracks on the left and right sides of the hole expanded into an inclined plane.

For SN0-4, the lateral pressure is $1.5 \mathrm{MPa}$, and point $\mathrm{A}$ is also before point $\mathrm{B}, \sigma_{i}=19.26 \mathrm{MPa}$, and it is similar to SN0-1 and SN0-2. According to the image captured, the primary crack is the shear crack on the left of the hole, $\sigma_{p}=26.36$ $\mathrm{MPa}$ (point $\mathrm{C}$ ); at this time, 3 main cracks appeared, all distributed around the hole, 2 shear cracks near the hole and 1 tensile crack at the bottom of the hole. At point D after the peak, the specimen cracks further expanded, but no new cracks were added; until point $\mathrm{E}$ after the peak, no new cracks are generated, and the shear cracks on the left and right sides of the hole expand into an inclined T plane.

It can be found that the crack expansion law of the specimen is as follows: The failure modes of all specimens are the same, and the failure modes of the specimens are all that the shear cracks on the left and right sides of the hole expand and penetrate a reverse inclined plane or inclined T plane; the primary cracks of each specimen are mostly shear cracks around the hole (located on the left and right parts of the hole), followed by tensile cracks around the hole (located on the upper and lower parts of the hole). The main cracks of each specimen are between 3 and 5. The initiation point of the specimens SN0-1, 0-2, and 0-3 is closer to the $\mathrm{E}_{50}$ point; this 


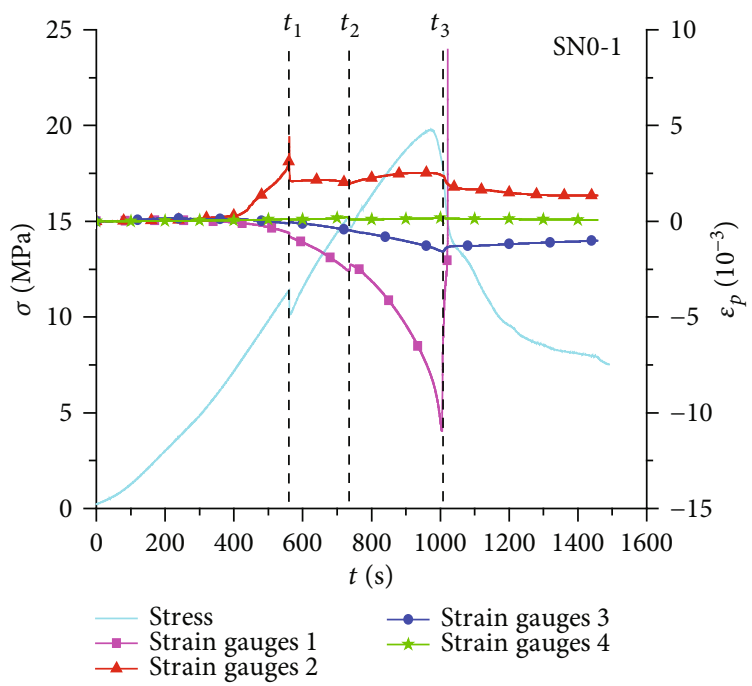

(a)

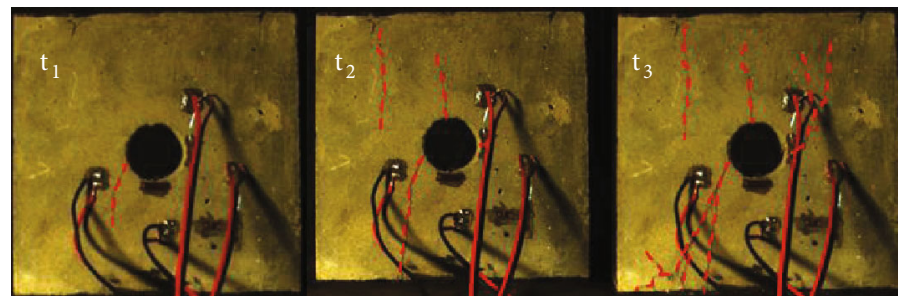

(b)

FIgURE 10: (a) Relationship between local strain and stress of specimen SN0-1 with loading time. (b) The relationship between the crack growth shape of specimen SN0-1 and loading time.

shows that under the condition of low lateral pressure, the primary point of the specimens can be referenced by the $\mathrm{E}_{50}$ point of the specimen. Each specimen has no obvious residual strength stage, indicating that the specimen has strong plasticity.

4.2. Local Strain Characteristics. According to the analysis of the failure mode and crack propagation and transfixion of the specimen, it can be found that the stress-strain of the specimen is closely related to the crack transfixion mode and crack propagation. A resistance strain gauge is arranged on a compression specimen with a lateral pressure of $0 \mathrm{MPa}$, a static strain gauge is used to complete the local strain data collection, and the collection frequency is 10 data per second. At the same time, an HD industrial camera is used to record the crack growth of the entire specimen and analyze the local strain characteristics of the specimen. The cracks around the hole are usually divided into five types (Figure 6); strain gauge 1 and strain gauge 2 are set near the hole, which measure the local strain at the initial stage of crack occurrence on the right side and lower part of the hole, respectively. The strain gauge 3 and the strain gauge 4 are set far from the hole to monitor the local strain in the vertical and horizontal directions during the crack propagation process.

The resistance strain gauge can directly reflect the small deformation that occurs after the structure is stressed; when a crack propagates through the strain gauge, the measured strain value is equal to the sum of the true strain on both sides of the crack and the crack width; this phenomenon is called the "strain jump." If the crack propagation is large, the strain here will increase rapidly, and the strain gauge may peel off from the specimen; at this time, the strain value after the strain jump will not be analyzed and discussed in this article.

The relationship curve of local strain and stress with the time of SN0-1 specimens and crack growth morphology are drawn as shown in Figure 10. It can be found from the figure that 4 pieces of high-precision resistance strain gauges have 3 obvious "strain jumps" $t_{1}, t_{2}$, and $t_{3}$. At the beginning of loading $(t \leq 300 \mathrm{~s})$, the local tensile strain and compressive strain are very small; as the axial stress continues to increase $(t>300 \mathrm{~s})$, the local tensile and compressive strains of the specimen begin to increase linearly like the axial stress. At $t_{1}=560.52 \mathrm{~s}$, the stress curve has a small drop, and strain gauges 1,2, 3, and 4 all have "strain jumps," which indicates that the specimen has a macroscopic crack, and the primary crack is the strain gauge 2 directly below the hole; at this time, the measured strains of strain gauges $1 \sim 4$ are $0.62 \times 10^{-3},+3.20 \times 10^{-3},-0.12 \times 10^{-3}$, and $+0.12 \times 10^{-3}$, respectively. At $t_{2}=736.70 \mathrm{~s}$, strain gauge 1 increased rapidly, and strain gauges 1 and 4 all showed strain jumps, especially strain gauge 1 which showed a large strain jump; it shows that at this time, the shear cracks on the lateral of the hole have begun to expand, and the location is on the right of the hole, at the strain gauge 1 . At this time, the measured strains of strain gauges $1 \sim 4$ are $-2.45 \times 10^{-3},+1.96 \times 10^{-3},-0.46 \times$ 


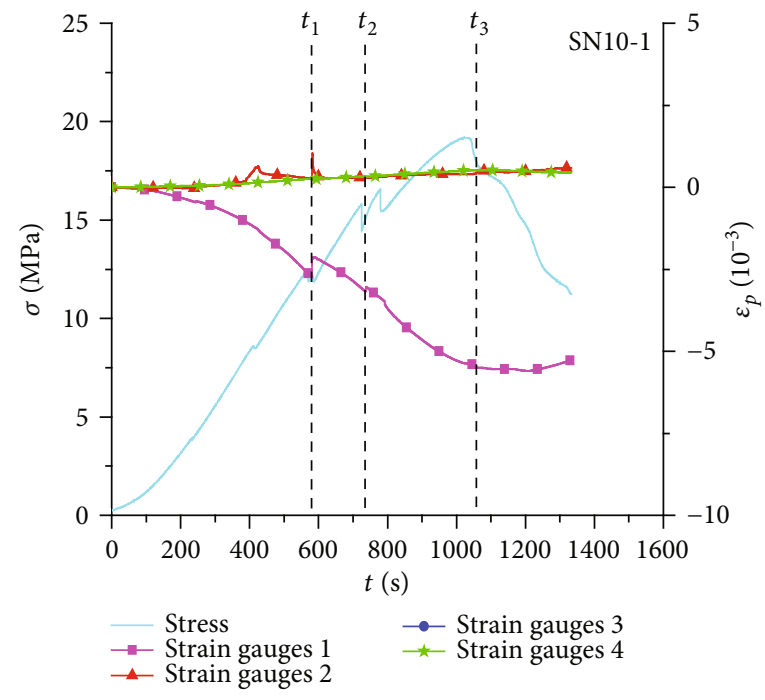

(a)

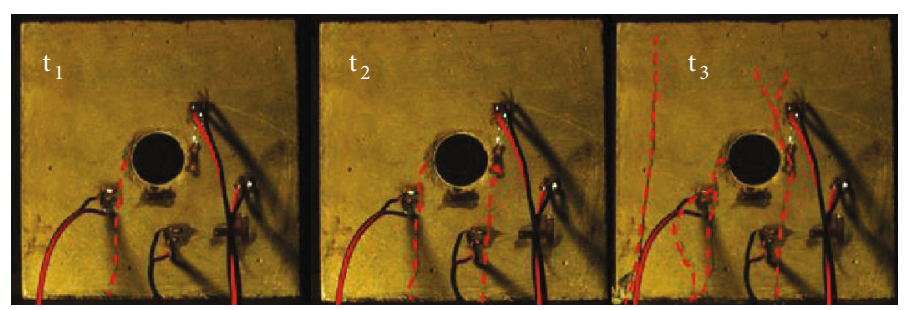

(b)

FIGURE 11: (a) Relationship between local strain and stress of specimen SN10-1 with loading time. (b) The relationship between the crack growth shape of specimen SN10-1 and loading time.

$10^{-3}$, and $+0.08 \times 10^{-3}$, respectively. At $t_{3}=1005.90 \mathrm{~s}$, the peak of the specimen has been experienced, the four strain gauges all have strain jumps, and at the same time, the stress decreases rapidly with time. The surface cracks have further transfixed at this time, and the time bearing capacity has further decreased; strain gauge 1 fails from here. The measured strains of strain gauges $2 \sim 4$ are $+2.38 \times 10^{-3},-1.57 \times 10^{-3}$, and $+0.18 \times 10^{-3}$, and the strain values at this time are all peaks.

The peak strength of this specimen is $19.78 \mathrm{MPa}$, peak load time $t_{\mathrm{p}}=973.08 \mathrm{~s}$, and the strain measured by strain gauges $1 \sim 4$ are $-8.08 \times 10^{-3},+2.52 \times 10^{-3},-1.36 \times 10^{-3}$, and $+0.15 \times 10^{-3}$. It is easy to find that the local strain measured by each strain gauge does not show a peak at this time; this is because although the specimen has reached its peak strength, it still has a certain load-bearing capacity, and the deformation will not have a peak.

Combined with the above analysis, the priority of crack growth is as follows: the first is the tensile cracks at the upper and lower parts of the hole, and then the shear cracks at the left and right parts. Finally, the shear cracks and the tensile cracks form an inclined plane. The bearing capacity of the specimen drops sharply, and finally, a bevel T failure mode is formed.

The relationship curve of local strain and stress with the time of SN10-1 specimen and the crack growth mor- phology is drawn as shown in Figure 11. The strain gauge 3 used in the local strain test is clearly unstable, so it is not listed in the figure. From Figure 11, it can be found that there are 3 obvious "strain jumps" in the 4 highprecision resistance strain gauges. At the beginning of loading $(t \leq 200 \mathrm{~s})$, the local tensile and compressive strains are both very small; as the axial stress continues to increase $(t>200 \mathrm{~s})$, the local tensile and compressive strains of the specimen begin to be linear like the axial stress increase. At $t_{1}=580.80 \mathrm{~s}$, the stress curve has a small drop; strain gauges 1, 2, and 4 all have "strain jumps," which means that the specimen has macrocracks, and the primary crack is at the strain gauge 1 on the right side of the hole; the photo capture found that this is indeed the case. At this time, the strains measured by strain gauges 1,2 , and 4 are $-2.73 \times 10^{-3},+0.21 \times 10^{-3}$, and $+0.30 \times 10^{-3}$. At $t_{2}=737.20 \mathrm{~s}$, strain gauge 1 showed a small strain jump, and the stress curve dropped at this time, indicating that the shear cracks around the hole (on the right) continued to expand and also the internal cracks of the specimen further transfixion; the strains measured by strain gauge 1,2 , and 4 are $-3.17 \times 10^{-3},+0.30$ $\times 10^{-3}$, and $+0.33 \times 10^{-3}$. At $t_{3}=1057.10 \mathrm{~s}$, the peak value of the specimen has been experienced, and strain gauges 1 , 2 , and 4 all have strain jumps; at the same time, the stress decreases rapidly with time, the surface cracks have further 


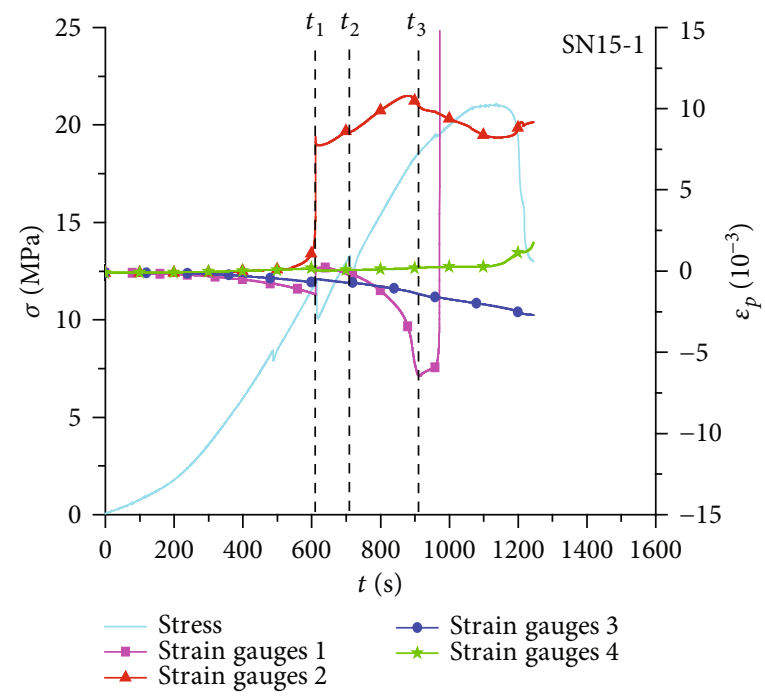

(a)

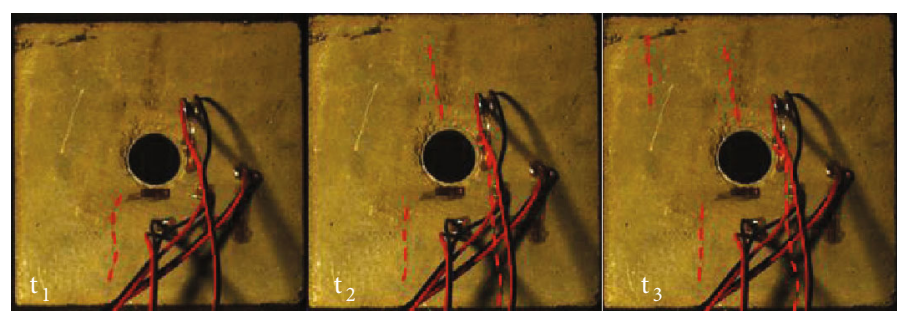

(b)

FIGURE 12: (a) Relationship between local strain and stress of specimen SN15-1 with loading time. (b) The relationship between the crack growth shape of specimen SN15-1 and loading time.

transfixion, and the bearing capacity has further decreased. The strain measured by strain gauges 1,2 , and 4 is $5.46 \times 10^{-3},+0.43 \times 10^{-3}$, and $+0.52 \times 10^{-3}$.

The peak strength of the specimen is $19.18 \mathrm{MPa}$. Peak load time $t_{\mathrm{p}}=1029.96 \mathrm{~s}$, and the strain measured by strain gauges 1,2 , and 4 are $-5.37 \times 10^{-3},+0.40 \times 10^{-3}$, and +0.50 $\times 10^{-3}$. It is easy to find that the local strain measured by the strain gauge does not show a peak at this time; this is because although the specimen has reached the peak strength, it still has a bearing capacity, and the deformation does not appear a peak. Strain gauges 2 and 4 have almost always increased with time, and their tensile strain has been increasing.

Combined with the above analysis, the priority of crack propagation is almost the same as specimen SN0-1, first the tensile cracks at the upper and lower parts of the hole, then the shear cracks at the left and right parts, and finally the shear cracks and the tensile cracks form an inclined plane; the bearing capacity of the specimen drops sharply, and finally, a bevel $\mathrm{T}$ type failure mode is formed.

The relationship curve of local strain and stress with the time of SN15-1 specimen and the crack growth pattern is drawn as shown in Figure 12. It can be found from Figure 12 that there are 3 obvious "strain jumps" of the 4 high-precision resistance strain gauges. At the beginning of loading ( $t \leq 200 \mathrm{~s})$, the local tensile and compressive strains are both very small. As the axial stress continues to increase $(t>200 \mathrm{~s})$, the local tensile and compressive strains of the specimen begin to be linear like the axial stress increase. At $t_{1}=611.90 \mathrm{~s}$, the stress curve has a small drop, and the strain gauges 1, 2, and 3 have obvious "strain jumps," which indicates that the specimen has appeared macroscopic cracks, and this should be the primary crack, that is, the upper and lower laterals of the hole are the first to occurred crack. At this time, the strains measured by strain gauges 1 to 4 are $1.33 \times 10^{-3},+6.15 \times 10^{-3},-0.54 \times 10^{-3}$, and $+0.28 \times 10^{-3}$. At $t_{2}=708.10 \mathrm{~s}$, the stress curve showed a smaller drop, and strain gauges 1 and 2 showed smaller strain jumps, indicating that the shear cracks around the hole (on the right) began to expand and the internal cracks of the specimen were further transfixed; at this time, the strain measured by strain gauges 1 to 4 are $-0.13 \times 10^{-3},+8.77 \times 10^{-3},-0.62 \times 10^{-3}$, and $+0.17 \times 10^{-3}$. At $t_{3}=905.70 \mathrm{~s}$, the specimen reaches the yield stage, and the stress curve drops rapidly with time, indicating that the crack has further transfixed at this time, and the bearing capacity of the specimen is further reduced; the strains measured by strain gauges 1 to 4 are $-6.03 \times 10^{-3}$, + $10.38 \times 10^{-3},-0.26 \times 10^{-3}$, and $+0.29 \times 10^{-3}$. Afterward, within a short period, the value measured by strain gauge 1 increases rapidly, indicating that it was damaged. The peak 


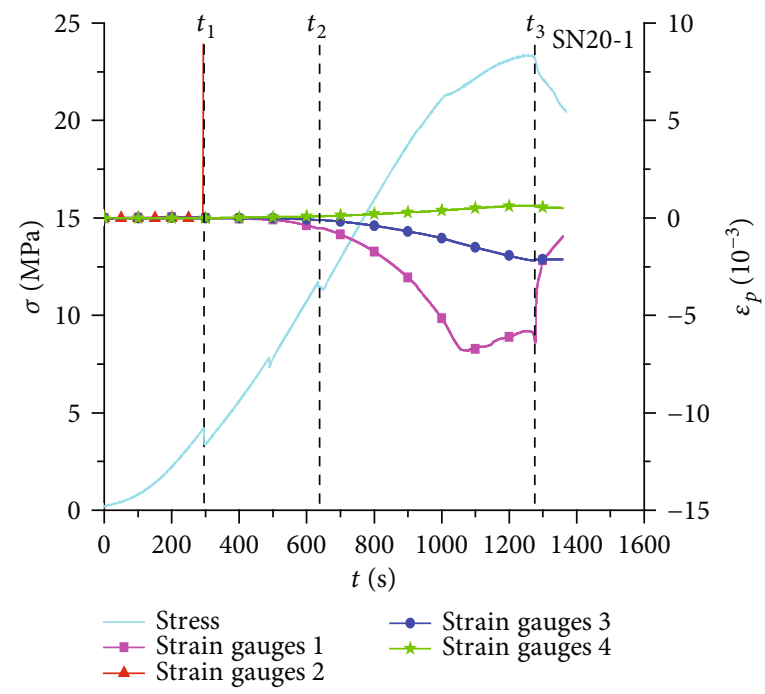

(a)

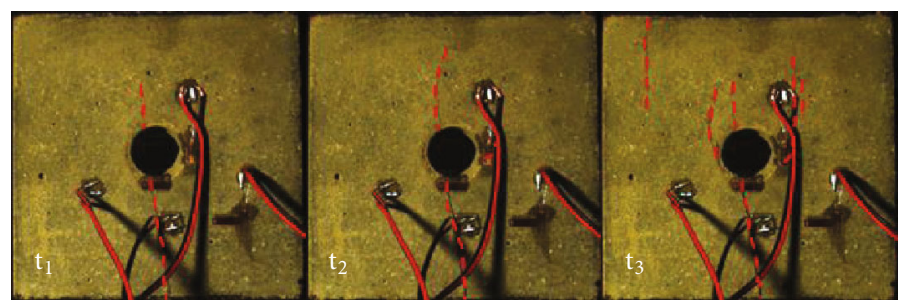

(b)

FIgURE 13: (a) Relationship between local strain and stress of specimen SN20-1 with loading time. (b) The relationship between the crack growth shape of specimen SN20-1 and loading time.

intensity of the specimen is $21.06 \mathrm{MPa}$, peak load time $t_{\mathrm{p}}=$ $1136.16 \mathrm{~s}$, and it is easy to find that the local strain measured by the strain gauge does not show a peak at this time; this is because although the specimen has reached the peak strength, it still has a certain bearing capacity, and the deformation does not appear a peak. The strains measured by strain gauges $2 \sim 4$ are $+8.28 \times 10^{-3},-2.06 \times 10^{-3}$, and +0.47 $\times 10^{-3}$. Strain gauges 3 and 4 have almost always increased with time, and their compressive and tensile strains have been increasing.

Combined with the above analysis, the priority of crack growth is almost the same as specimen SN0-1. First, the tensile cracks at the upper and lower parts of the hole, then the shear cracks at the left and right parts, and finally the shear cracks and the tensile cracks form an inclined plane, the bearing capacity of the specimen drops sharply, and finally, an oblique T-shaped failure mode is formed.

The relationship curve of local strain and stress with the time of SN20-1 specimen and the crack growth pattern is drawn as shown in Figure 13. It can be found that there are 3 obvious "strain jumps" of the 4 high-precision resistance strain gauges. In the initial stage of loading ( $t \leq 500 \mathrm{~s})$, the local tensile strain and compressive strain are both very small; as the axial stress continues to increase $(t>500 \mathrm{~s})$, the local tensile and compressive strain of the specimen begin to be linear like the axial stress increase. At $t_{1}=294.84 \mathrm{~s}$, the stress curve showed a more obvious drop, and the measured value of strain gauge 2 also shows a more obvious "strain jump," indicating that the strain gauge 2 has been damaged and that the specimen has appeared macroscopic cracks, and this should be the primary crack, that is, the upper and lower parts of the hole are the first to crack. At this time, the strain measured by strain gauge 1 is $+0.05 \times 10^{-3}$; the strain measured by the strain gauge 3 is extremely small, and it is not counted here; the strain measured by strain gauge 4 is $+0.01 \times 10^{-3}$. At $t_{2}=632.10 \mathrm{~s}$, the stress curve showed a smaller drop, and the strain gauge 1 showed a smaller strain jump, indicating that the shear cracks around the hole (on the right) began to expand and the internal cracks of the specimen were further transfixed; at this time, the strain measured by strain gauges 1,3 , and 4 is, respectively, $-0.51 \times 10^{-3},-0.10 \times 10^{-3}$, and $+0.10 \times 10^{-3}$. At $t_{3}=$ $1256.04 \mathrm{~s}$, the specimen has just reached the peak strength, and the strain gauges 1,3 , and 4 have strain jumps, indicating that the crack has transfixed further at this time, and the bearing capacity of the specimen will rapidly decrease in the next few seconds. At this time, the strains measured by strain gauges 1,3 , and 4 are $-6.74 \times 10^{-3},-1.30 \times 10^{-3}$, and $+0.46 \times 10^{-3}$.

The peak strength of this specimen is $23.34 \mathrm{MPa}$, and peak load time $t_{\mathrm{p}}=1256.04 \mathrm{~s}$. It is easy to find that the local strains measured by strain gauges 3 and 4 both reach the 
maximum value at this time. Strain gauges 3 and 4 have almost always increased with time, and their compressive and tensile strains have been increasing.

Combining the above analysis, the priority of crack growth is consistent with that of the specimen SN0-1. First, the tensile cracks at the upper and lower parts of the hole, then the shear cracks at the left and right parts, and finally the shear cracks form an inclined plane and finally form the single bevel type III failure mode.

Based on the above-mentioned strain characteristics near the cracks in the rock specimens with holes, it is easy to find that the failure modes of the specimens are relatively consistent, and the number of local strain jumps is almost the same (3 locations). The first local strain jump times of specimens SN0-1, SN10-1, SN15-1, and SN20-1 are $560.52 \mathrm{~s}, 580.80 \mathrm{~s}$, $611.90 \mathrm{~s}$, and $294.84 \mathrm{~s}$, respectively, that is, under the same lateral pressure; with the increase of the reinforcement thickness, the time for the specimen to first appear macrocracks in the compression process shows a phenomenon of first increasing and then decreasing. The local strain measured by the SN0-1, SN10-1, and SN15-1 strain gauges did not show a peak at the peak strength of the specimen; this is because although the specimen has reached its peak strength, it still has a certain load-bearing capacity, and the deformation will not have a peak. When the reinforcement thickness is less than $1.5 \mathrm{~mm}$, the crack transfixion time shows a slight increase first and then decreases with the increase of the reinforcement thickness. When the reinforcement thickness reaches $2 \mathrm{~mm}$, the crack transfixion time increases significantly, indicating that the reinforcement effect at this time is the most significant.

\section{Conclusions}

In this paper, a biaxial compression test of a single-hole rock-like material is carried out, the influence of lateral pressure and different reinforcement thickness on the crack transfixion law around the hole of the rock-like material is explored, and the local strain characteristics of the rock-like material are analyzed. The research results are as follows:

(1) Under the same lateral pressure, the peak strength of the specimen increased by $1.42 \% \sim 33.04 \%$ with the increase of the reinforcement thickness; with the increase of reinforcement thickness, the positive effect of thickening thickness on the peak strength becomes more obvious; with the same reinforcement thickness, the peak strength of the specimen increased by $3.34 \% \sim 50.26 \%$; with the increase in lateral pressure, the positive effect of lateral pressure on peak strength becomes more obvious by the increase of lateral pressure

(2) Increasing the lateral pressure can significantly reduce the primary tensile cracks of the specimen. The primary tensile cracks and remote cracks of the specimen are significantly reduced with the reinforcement thickness increases, and the failure surface of the specimen gradually tends to the middle of the specimen

(3) The failure modes of specimens with holes can be divided into five categories: single bevel type I, single bevel type II, single bevel type III, bevel T type, and single part shear type. These five types of failure modes are all developed by shear cracks and remote cracks, and primary tensile cracks do not cause fracture surfaces.

\section{Data Availability}

All data and models generated or used during the study appear in the submitted article.

\section{Conflicts of Interest}

The authors declare that they have no conflicts of interest.

\section{Acknowledgments}

This research is supported by the National Natural Science Foundation of China (Nos. 51774131, 51274097). The authors are thankful for all of the support for this basic research.

\section{References}

[1] J. B. Martino and N. A. Chandler, "Excavation-induced damage studies at the Underground Research Laboratory," International Journal of Rock Mechanics and Mining Sciences, vol. 41, no. 8, pp. 1413-1426, 2004.

[2] E. Hoek and E. T. Brown, "Practical estimates of rock mass strength," International Journal of Rock Mechanics and Mining Sciences, vol. 34, no. 8, pp. 1165-1186, 1997.

[3] N. Bahrani and P. K. Kaiser, "Strength degradation of nonpersistently jointed rockmass," International Journal of Rock Mechanics and Mining Sciences, vol. 62, pp. 28-33, 2013.

[4] A. Mortazavi, F. P. Hassani, and M. Shabani, "A numerical investigation of rock pillar failure mechanism in underground openings," Computers and Geotechnics, vol. 36, no. 5, pp. 691697, 2009.

[5] B. Van De Steen, A. Vervoort, and J. A. L. Napier, "Observed and simulated fracture pattern in diametrically loaded discs of rock material," International Journal of Fracture, vol. 131, no. 1, pp. 35-52, 2005.

[6] E. Z. Lajtai and V. N. Lajtai, "The collapse of cavities," International Journal of Rock Mechanics and Mining Sciences \& Geomechanics Abstracts, vol. 12, no. 4, pp. 81-86, 1975.

[7] A. Fakhimi, F. Carvalho, T. Ishida, and J. F. Labuz, "Simulation of failure around a circular opening in rock," International Journal of Rock Mechanics and Mining Sciences, vol. 39, no. 4, pp. 507-515, 2002.

[8] Q. Yin, H. W. Jing, and H. J. Su, "Investigation on mechanical behavior and crack coalescence of sandstone specimens containing fissure-hole combined flaws under uniaxial compression," Geosciences Journal, vol. 22, no. 5, pp. 825-842, 2018.

[9] J. Hou, AE Experiment Study on Damage and Failure Processes of Rock with Hole, [M.S. thesis], Northeastern University of China, 2009. 
[10] H.-R. Rong, H.-L. Wang, Z.-S. Wang, M.-M. Feng, B.-L. Mu, and Z.-H. Wang, "Experimental research on influence of size effect on compression mechanical strength and failure characteristics of rock," Standard Design (in Chinese), vol. 61, no. 8, pp. 96-100, 2017.

[11] J.-H. Cui and Q.-F. Liang, "Experimental and simulation analysis of influence of hole diameter on rock mechanical properties," Journal of Shaoxing University (Natural Science) (in Chinese), vol. 39, no. 3, pp. 38-45, 2019.

[12] N. C. Gay, "Fracture growth around openings in large blocks of rock subjected to uniaxial and biaxial compression," International Journal of Rock Mechanics and Mining Sciences \& Geomechanics Abstracts, vol. 13, no. 8, pp. 231-243, 1976.

[13] M. Tao, H. Zhao, A. Momeni, Y. Wang, and W. Cao, "Fracture failure analysis of elliptical hole bored granodiorite rocks under impact loads," Theoretical and Applied Fracture Mechanics, vol. 107, article 102516, 2020.

[14] H. F. Xie, Q. H. Rao, Q. Xie, Z. Y. Li, and Z. Wang, "Effect of holes on in-plane shear (mode II) crack sub-critical propagation of rock," Journal of Central South University of Technology, vol. 15, no. S1, pp. 453-456, 2008.

[15] R.-J. Cui, Y.-S. Zhao, Y.-P. Wang, and D.-L. Xiao, “Analysis on the failure mechanism of incomplete specimens under compression conditions," Mining Research and Development (in Chinese), vol. 39, no. 11, pp. 84-90, 2019.

[16] R. P. Janeiro and H. H. Einstein, "Experimental study of the cracking behavior of specimens containing inclusions (under uniaxial compression)," International Journal of Fracture, vol. 164, no. 1, pp. 83-102, 2010.

[17] L. J. L. Yuanhai, T. Xiaojie, Y. Shuo, and L. Dezhu, "Simulation analysis of mechanical properties of the soft rock mass with holes and fractures," Journal of Mining \& Safety Engineering, vol. 37, no. 3, pp. 594-603, 2020.

[18] X. Wang, Y. Jiang, and B. Li, "Experimental and numerical study on crack propagation and deformation around underground opening in jointed rock masses," Geosciences Journal, vol. 21, no. 2, pp. 291-304, 2017.

[19] R. H. C. Wong, P. Lin, and C. A. Tang, "Experimental and numerical study on splitting failure of brittle solids containing single pore under uniaxial compression," Mechanics of Materials, vol. 38, no. 1-2, pp. 142-159, 2006.

[20] S. Y. Wang, S. W. Sloan, D. C. Sheng, and C. A. Tang, "Numerical analysis of the failure process around a circular opening in rock," Computers and Geotechnics, vol. 39, pp. 8-16, 2012.

[21] L. X. L. I. Chongjin and L. I. Diyuan, "Particle flow analysis of fracture characteristics of marble with a single hole," Chinese Journal of Engineering (in Chinese), vol. 39, no. 12, pp. 17911801, 2017. 